\title{
Determining the Dependencies of Engineering Competencies for Engineering Practice: An Exploratory Case Study
}

\section{Dr. Jillian Seniuk Cicek, University of Manitoba}

Dr. Jillian Seniuk Cicek is an Assistant Professor in the Centre for Engineering Professional Practice and Engineering Education at the University of Manitoba, in Canada. She teaches technical communication. Her areas of investigation include program evaluation; outcomes-based teaching and assessment; engineering competencies; instructor pedagogical practices and belief-systems; engineering epistemology; and student culture, diversity, perspectives, and identity.

\section{Robert Renaud PhD, University of Manitoba}

Dr. Robert Renaud is cross-appointed as an Associate Professor in the Centre for Engineering Professional Practice and Engineering Education, and is the Head of the Department of Educational Administration, Foundations, and Psychology at the University of Manitoba, in Winnipeg, Canada. He teaches assessment, program evaluation, and research methods. His main areas of research interest include program evaluation, student assessment, teaching effectiveness, and quantitative methods. 


\title{
Determining the Dependencies of Engineering Competencies for Engineering Practice: An Exploratory Case Study
}

\begin{abstract}
Similar to the changes brought about by ABET's adoption of student learning outcomes, changes to engineering accreditation requirements in Canada in 2009 initiated a shift to outcomes-based education and emphasis on continual program improvement. A list of 12 attributes was introduced competencies that can be mapped on to the ABET General Criterion 3: Student Outcomes. The Canadian Engineering Accreditation Board (CEAB) requires all students graduating from CEAB accredited engineering programs demonstrate these competencies. This has presented a challenge: how best to teach and assess them? Generally, the CEAB graduate attributes were/are accepted as offered: 12 individual competencies, with emphasis often placed on the first listed - Engineering Knowledge, Problem Analysis, Investigation, Design, and Engineering Tools - the more 'traditional' engineering skills - even if this emphasis was not intended by CEAB. In fact, research in the field indicates that teamwork and communication skills - competencies found in the 'middle' of the list - are top competencies for engineering practice. Additionally, the need to investigate potential clusters of competencies has been emphasized in this research, identified as a gap in both engineering education and research.
\end{abstract}

Considering the research, and motivated to inform engineering education curricular design and improvement at the University of Manitoba, an exploratory case study was designed in part to investigate how the CEAB graduate attributes cluster for a new engineer in engineering practice as perceived by key engineering stakeholders. The data consisted of perceived similarities between each possible pair of graduate attributes collected from engineering student, faculty and industry stakeholders. Multidimensional scaling analysis showed that the 12 graduate attributes can be conceptualized as four clusters, which we have suggested be titled, Problem Solving Skills, Interpersonal Skills, Ethical Reasoning, and Creativity and Innovation. These findings, supported by the relevant literature, highlight the need to further explore how engineering competencies cluster in practice to add empirical support for program changes aimed toward educating the whole engineer.

\section{Introduction and Objectives}

Over the past 20 years, engineering accreditation boards across the world have embraced outcomesbased assessment as part of their accreditation requirements ${ }^{1}$. Accredited engineering programs have to demonstrate that their graduating students have competencies in a variety of knowledge, skill, attitude, value and behaviour capacities. In Canada, the Canadian Engineering Accreditation Board (CEAB) governs accredited engineering programs. Twelve graduate attributes have been identified by CEAB in which engineering students must be proficient:

1. A knowledge base for engineering

2. Problem analysis

3. Investigation

4. Use of engineering tools

5. Design 
6. Individual and teamwork

7. Communication skills

8. Professionalism

9. Impact of engineering on society and the environment

10. Ethics and equity

11. Economics and project management

12. Lifelong learning

As with other accreditation boards, such as ABET, it is the engineering program seeking accreditation that must devise the outcomes-based teaching and assessment measures to facilitate students' learning in these areas ${ }^{1}$. To some extent, thus far in Canada, due to the pressures of accreditation, approaches to this problem could be generalized as efforts to teach and assess the CEAB graduate attributes by individually and equitably attending to each attribute on the list, despite acknowledgment by the Washington Accord that whilst all attributes are important, they should not necessarily be appointed equal weight ${ }^{2}$. This individual treatment of engineering competencies was also reflected in the treatment of the ABET learning outcomes at the onset of their accreditation changes to outcomes-based assessment. For example, in an unpublished review of the Journal of Engineering Education from 2006-2011 conducted by the first author to explore publications on the teaching and assessing of the engineering 'professional skills' (e.g., teamwork, communication skills, ethics, professionalism, and lifelong learning) in response to Shuman et al.'s 2005 article $^{3}, 11$ out of the 12 articles that met the criteria focused exclusively on one or two student outcomes ${ }^{4-15}$. During this time period, there were no articles published in this journal that considered the conceptual or theoretical understanding of all of the engineering competencies.

The same is true in Canadian engineering education research, where much of the focus is on the 12 graduate attributes as individual components. For example, in the 2014 Canadian Engineering Education Association-Association canadienne de l'éducation en génie national (CEEA-ACEG) annual conference, 31 out of 105 papers published in the proceedings refer to the CEAB graduate attributes. Of those, 27 either discuss the 12 graduate attributes collectively, or focus on one, two, or at the most, three attributes at once, essentially treating them as separate components or the collective dozen ${ }^{16-42}$. Within those, only authors of five of these papers implicitly or explicitly state the inauthenticity of considering the attributes individually, or refer to potential relationships or connections between them $^{19,25,31,35-36}$.

Problematic in the isolated approach is the tendency to ignore that engineering competencies 'overlap and are entwined' (p. 453) ${ }^{43}$. One could argue that isolating engineering competencies in engineering curricula is inauthentic to engineering practice, and therefore potentially less effective way of teaching and assessing the student engineer. In order to consistently and effectively design engineering curricula to reflect engineering practice, faculty, students, and other engineering stakeholders need to have a clear and common understanding of what the engineering competencies are, what their relative importance is, and a shared conceptual understanding of how they interact in practice. Research on relative importance of engineering competencies has been minimal ${ }^{44-51}$, with only preliminary considerations of interrelationships among competencies ${ }^{46-48,51-53}$. In an important piece of research, Passow (2012) presents the results of a seven-year survey that asked engineering graduates to value each of the ABET General Criterion 3: Student Outcomes in relation to their professional careers ${ }^{53}$. Passow (2012) concluded that among other things, 'faculty... should consider placing special emphasis 
on the 'top cluster' competencies' (p. 112) ${ }^{53}$. In a connected piece of research, published in 2017, Passow and Passow reiterate this need ${ }^{51}$. This work paves the way for a new direction in engineering education research to explore how engineering stakeholders conceptually understand or 'cluster' the graduate attributes.

In a large research university in Western Canada, an exploratory case study was designed with the overarching objective to investigate whether the engineering programs in the Faculty of Engineering emphasized the CEAB graduate attributes to reflect their reported importance by student, faculty and industry member stakeholders. One purpose of the study was to determine how the CEAB graduate attributes cluster - or group - in practice for an Engineering-in-Training (EIT) at the beginning of his/her engineering career so that engineering education can be designed to more closely reflect engineering practice. In other words, when an engineer is engaged in an activity that requires one graduate attribute, what is the perception that the engineer will require the knowledge, skills, attitudes, values, or behaviours of another graduate attribute in order to perform that task competently? In this study, this was defined as the 'perceived dependency' of one graduate attribute on another. The perceived dependency data were used to determine how the graduate attributes cluster in practice for the purpose of informing curricular design.

This part of the study was guided by the following research questions:

$R Q 1$. What is the perceived dependency of each of the $12 C E A B$ graduate attributes on every other CEAB graduate attribute for all engineering stakeholders (i.e., students, faculty, and industry) in the Faculty of Engineering at the University of Manitoba?

$R Q$ 2. How much does the perceived dependency of each CEAB graduate attribute on every other $C E A B$ graduate attribute vary between engineering stakeholder groups (i.e., students vs. faculty vs. industry)?

$R Q$ 3. How do the perceived similarities of the CEAB graduate attributes cluster together across all engineering stakeholders?

Some of the findings from this part of this exploratory research study are discussed in this research paper. They will be expanded upon fully in future publications.

\section{Research Design and Methods}

This research was designed as an exploratory case study. The overarching objective of this study was to investigate how the emphasis on the CEAB graduate attributes in the Faculty of Engineering programs at the University of Manitoba reflects their reported importance by key stakeholders. For the portion of the study reported on in this paper, the researcher was concerned with what the various engineering stakeholders perceived regarding the dependency of one CEAB graduate attribute on another. The case was bounded by place and the individuals of interes ${ }^{54}$, specifically the engineering students, faculty, and industry members associated with the Departments of Biosystems, Civil, Electrical and Computer, and Mechanical Engineering in the Faculty of Engineering at the University of Manitoba. The percentage to which every graduate attribute is dependent on, or requires, every other graduate attribute for an Engineer-in-Training (EIT) at the beginning of his/her career as perceived by University of 
Manitoba senior undergraduate students in Capstone courses, engineering faculty, and Manitoba industry stakeholders was determined.

\subsection{Research Site}

The research site was the Faculty of Engineering at the University of Manitoba. The University of Manitoba is a large research institution located in Winnipeg, Canada. Its Faculty of Engineering houses four engineering departments and offers Bachelor of Science degrees in five disciplines: Biosystems, Civil, Electrical, Computer, and Mechanical Engineering. Each program is accredited by the CEAB. Approval for this research was obtained from this university's research ethics board.

\subsection{Research Participants}

Engineering stakeholders were purposefully selected as participants in this exploratory research study based on their capacity to support the research objectives ${ }^{54,55}$. Participants for this part of the study comprised of three University of Manitoba engineering stakeholder groups, with populations representative of the 2015-2016 academic year:

- Senior year undergraduate engineering students enrolled in Capstone in the Faculty of Engineering $(\mathrm{N}=235)$

- Engineering Faculty from the Faculty of Engineering: Professors, Instructors, Administrators, and Engineers-in-Residence ( $\mathrm{N}=91)$

- Manitoba industry members associated with the Faculty of Engineering through Friends of Engineering $(\mathrm{N}=70)$ (augmented by industry members associated with the Faculty of Engineering industry forums or professional licensure associations)

An adequate sample size for the dependency data was collected based on the targeted participant populations ${ }^{1}$, with 93 (39.6\% of 235) students, 40 (44.0\% of 91) faculty, and 29 (29.4\% of 70$)$ industry members responding, for a total of 162 respondents.

\subsection{Research Measures}

A closed-ended ratings questionnaire was designed to collect data from engineering stakeholders on the dependency of one graduate attribute on another graduate attribute. Five engineers (in residence at the university) and three senior engineering students completed a pilot version of the questionnaire to ensure that the instructions were sufficiently clear and the survey could be completed within the expected length of time.

The dependency data were collected for the purpose of determining potential clusters of the CEAB graduate attributes in engineering practice. For this research, 'clusters' were intellectualized as connections or relations between attributes, and 'connections' were theorized as the 'dependency' of one attribute on another. By establishing stakeholders' professional judgment of the degree to which they feel that one CEAB graduate attribute is dependent on, or requires another CEAB graduate attribute for use by an Engineer-in-Training (EITs) at the beginning of their career, a pattern of perceived dependencies could be determined amongst the graduate attributes. 
Participants were asked to rate the dependency of each of the 12 CEAB graduate attributes on every other CEAB graduate attribute by estimating the degree to which an Engineer-in-Training (EIT) at the beginning of his/her career who is doing something that involves the knowledge, skills, attitudes, values, or behaviours of one graduate attribute, depends on or requires the knowledge, skills, attitudes, values, or behaviours of another graduate attribute. Participants had five choices on which to base their perceptions: $0 \%, 25 \%, 50 \%, 75 \%$, or $100 \%$, which were described for participants as never, seldom, sometimes, often, or always depends on/requires, respectively. Participants were asked to consider each of the 12 graduate attributes in relation to every other graduate attribute in a one-way relationship as follows:

Based on your experience, please indicate on a percentage scale that ranges from $100 \%=$ total dependency to $0 \%=$ no dependency (see [scale] below), the degree to which you feel that the attribute listed on the left is dependent on, or requires, the attribute listed on the right for an Engineer-inTraining (EIT) at the beginning of his/her career. ${ }^{1}$

For example, in the first pair, you should think about the degree to which an Engineer-in-Training (EIT) at the beginning of his/her career who is doing something that involves A Knowledge Base for Engineering depends on, or requires, Problem Analysis. ${ }^{l}$

\begin{tabular}{|c|c|c|c|c|c|c|}
\hline & $100 \%$ & $75 \%$ & $50 \%$ & $25 \%$ & $0 \%$ & \\
\hline $\begin{array}{c}\text { A Knowledge } \\
\text { Base for } \\
\text { Engineering }\end{array}$ & & & & & & $\begin{array}{c}\text { Problem } \\
\text { Analysis }\end{array}$ \\
\hline
\end{tabular}

Engineering stakeholders' perceived dependency for each graduate attribute on every other graduate attribute was determined based on the mean for all stakeholder groups holistically, as well as for each stakeholder group separately (i.e., student, faculty and industry). From these data, analyses were performed to demonstrate how the graduate attributes cluster together.

\subsection{Dependency Data Analyses}

To answer $R Q 1$ - What is the perceived dependency of each of the 12 CEAB graduate attributes on every other CEAB graduate attribute for all engineering stakeholders (i.e., students, faculty and industry) in the Faculty of Engineering at the University of Manitoba? - the mean dependency for each pair of graduate attributes was calculated to determine the perceived dependency of each of the 12 CEAB graduate attributes on every other CEAB graduate attribute. These data were presented in tables illustrating one-way dependencies of each graduate attribute pair (see Table 4.1 in Findings).

Next, to answer $R Q 2$ - How much does the pattern of perceived dependencies of the CEAB graduate attributes vary between engineering stakeholder groups (i.e., students vs. faculty vs. industry)? a Pearson two-tailed correlation between the dependency ratings for each pair of stakeholder groups (i.e., student-faculty, student-industry, faculty-industry) was performed. It is important to note that correlations show only the similarity of the profiles between the stakeholder groups, and not how close the profiles are. To measure how close the profiles were, the sum of square differences was calculated for each group and the root mean square was derived to evaluate how close the dependencies were for each pair of stakeholders. These findings were used to determine which stakeholder group would be used for analysis for RQ 3. 
To answer RQ 3 - How do the CEAB graduate attributes cluster together based on the engineering stakeholders' perceived dependencies? - data were analyzed using Multidimensional Scaling (MDS). MDS is 'A technique that creates a map displaying the relative positions of a number of objects, given only a table of the distances between them. The map may consist of one, two, three, or even more dimensions. The program calculates either the metric or the non-metric solution. The table of distances is known as the proximity matrix. It arises either directly from experiments or indirectly as a correlation matrix ${ }^{56}$. MDS offers a visual representation of the perceived similarity between variables (i.e., graduate attributes) - indicated in a multidimensional space as the distances between points ${ }^{57}$ (i.e., the closer the points are in space, the higher the similarity between those points). MDS was chosen in order to explore the similarities in the dependencies of the pairs of CEAB graduate attributes, and if and how the graduate attributes cluster in distinct but related groups. The data from the group, All Engineering Stakeholders (i.e., the holistic data collected from students, faculty and industry stakeholders) were used for the MDS analysis based on the findings from the data analyses for RQ 2 (see above).

\section{Findings}

Participants were asked to rate the dependency of one CEAB graduate attribute on another CEAB graduate attribute for an EIT in practice at the beginning of her/his career. The following section reports on the $\mathrm{CEAB}$ graduate attribute dependencies from the holistic perspective of all engineering stakeholders associated with the Faculty of Engineering at the University of Manitoba in this case. The findings are organized by these research questions:

$R Q 1$ What is the perceived dependency of each of the 12 CEAB graduate attributes on every other CEAB graduate attribute for all engineering stakeholders (i.e., students, faculty and industry) in the Faculty of Engineering at the University of Manitoba?

$R Q 2$ How much does the pattern of perceived dependencies of the CEAB graduate attributes vary between engineering stakeholder groups (i.e., students vs. faculty vs. industry)?

$R Q 3$ How do the perceived similarities of the CEAB graduate attributes cluster together across all engineering stakeholders?

\subsection{Perceived Dependencies of CEAB Graduate Attributes Across All Engineering Stakeholder Groups}

For all engineering stakeholders in this case $(\mathrm{N}=162)$, the mean perceived dependencies of the $\mathrm{CEAB}$ graduate attributes ranged from $40.1 \%-88.7 \%$ with a mean of $61.4 \%$, with Ethics and Equity having the lowest dependency on Use of Engineering Tools, and Individual and Teamwork having the highest dependency on Communication Skills (see Table 4.1). 
Table 4.1

Mean perceived dependency of one $C E A B$ graduate attribute on another $C E A B$ graduate attribute across all engineering stakeholders $(N=162)$.

\begin{tabular}{|c|c|c|c|c|c|c|c|c|c|c|c|c|}
\hline$\rightarrow$ & B & A & IN & $\mathrm{E}$ & $\mathrm{ET}$ & $T$ & $S$ & $\mathrm{R}$ & IE & EE & $\mathrm{EP}$ & LL \\
\hline KB & & & & & & & & & & & & \\
\hline PA & & & & & & & & & $\begin{array}{l}55.4 \% \\
(30.0)\end{array}$ & $\begin{array}{l}51.5 \% \\
(33.3)\end{array}$ & & \\
\hline $\mathrm{IN}$ & & & & $\begin{array}{l}56.2 \% \\
(29.4)\end{array}$ & & & & & & & & \\
\hline $\mathrm{DE}$ & & & & & & & & & & & & \\
\hline ET & & & & & & & & & & & & \\
\hline IT & & & & & & & & & & & & \\
\hline CS & & & & & & & & & & & & \\
\hline PR & & & & & & & & & & & & \\
\hline IE & (26.4) & (27.8) & $\begin{array}{l}68.7 \% \\
(28.0)\end{array}$ & $\begin{array}{r}65.7 \% \\
(30.0) \\
\end{array}$ & & & & $\begin{array}{l}66.2 \% \\
(31.8) \\
\end{array}$ & & $\begin{array}{l}79.5 \% \\
(24.8) \\
\end{array}$ & & \\
\hline EE & 0.07 & $7.5 \%$ & $\begin{array}{r}50.2 \% \\
(34.1) \\
\end{array}$ & $\begin{array}{l}0.5 \% \\
35.2) \\
\end{array}$ & & & & $\begin{array}{r}79.9 \% \\
(27.6) \\
\end{array}$ & $\begin{array}{l}75.8 \% \\
(29.5)\end{array}$ & $\begin{array}{c}100 \% \\
(0.0)\end{array}$ & & \\
\hline EP & 40 & $0.1 \%$ & $\begin{array}{l}2.8 \% \\
30.4)\end{array}$ & $\begin{array}{l}4.7 \% \\
28.5) \\
\end{array}$ & $\begin{array}{l}62.7 \% \\
(26.8)\end{array}$ & & $\begin{array}{l}78.9 \% \\
(25.9)\end{array}$ & $\begin{array}{l}74.4 \% \\
(27.2)\end{array}$ & $\begin{array}{l}63.0 \% \\
(29.1)\end{array}$ & $\begin{array}{l}66.2 \% \\
(29.6)\end{array}$ & $\begin{array}{c}100 \% \\
(0.0)\end{array}$ & (30.) \\
\hline LL & $\begin{array}{l}.1 \% \\
9.9)\end{array}$ & $\begin{array}{l}.4 \% \\
9.6)\end{array}$ & $\begin{array}{l}5.3 \% \\
29.8)\end{array}$ & $\begin{array}{l}59.0 \% \\
(32.1)\end{array}$ & 65.4 & & $65.4 \%$ & $\begin{array}{l}69.3 \% \\
(31.3)\end{array}$ & $\begin{array}{l}61.3^{\circ} \\
(33.4\end{array}$ & $\begin{array}{l}63.3 \% \\
(32.2)\end{array}$ & & $(0.0$ \\
\hline
\end{tabular}

Note. 1. Standard deviations in brackets. 2. $\mathrm{KB}=$ Knowledge Base for Engineering; PA=Problem Analysis; IN=Investigation; DE=Design; ET=Use of Engineering Tools; IT=Individual and Teamwork; $\mathrm{CS}=$ Communication Skills; PR=Professionalism; IE=Impact of Engineering; EE=Ethics and Equity; $\mathrm{EP}=$ Economics and Project Management; $\mathrm{LL}=$ Lifelong Learning. 3. This table depicts one-way dependencies. The values in each cell represent the dependency the graduate attribute in the column on the left has on the graduate attribute in the row across the top. For example, the dependency of KB on $\mathrm{PA}$ is $67.4 \%$, whereas the dependency of PA on $\mathrm{KB}$ is $82.9 \%$. 4. Lowest and highest dependency score are highlighted.

\subsection{Variation in the Pattern of Perceived Dependencies of the CEAB Graduate Attributes Across Engineering Stakeholder Groups}

A Pearson two-tailed correlation was performed to evaluate how much the pattern of perceived dependencies of the CEAB graduate attributes varied across engineering stakeholder groups using the mean perceived dependency ratings of the pairs of CEAB graduate attributes as the unit of analysis (i.e., 12 graduate attributes multiplied by 11 possible pairings, $\mathrm{N}=132$ ). The findings suggest that pattern of perceived dependencies across stakeholder groups were fairly similar - $\mathrm{r}=0.87$ (studentfaculty), $r=0.79$ (student-industry), $r=0.84$ (faculty-industry) (see Table 4.2). 
Table 4.2

Correlations in the pattern of perceived mean dependencies of the CEAB graduate attributes for engineering stakeholders ( $N=132$ graduate attribute pairs).

\begin{tabular}{llll}
\hline Stakeholder & Students & Faculty & Industry \\
\hline Student & -- & $.87 * *$ & $.79 * *$ \\
Faculty & $.87 * *$ & -- & $.84 * *$ \\
Industry & $.79 * *$ & $.84 * *$ & -- \\
\hline
\end{tabular}

Note. ${ }^{* *}$ Correlation is significant at the 0.01 level (2-tailed).

The mean squared difference was calculated to evaluate how the pairs of dependencies of the CEAB graduate attributes varied between stakeholder groups. The root mean square for students, faculty, and industry ranged between 9.0-13.41, with a range from 1-31, suggesting that there was not much variation in the absolute dependencies of pairs of graduate attributes among stakeholders (see Table 4.3).

Table 4.3

Absolute dependencies between engineering stakeholders' perceived dependencies of pairs of the CEAB graduate attributes for engineering stakeholders ( $=132$ graduate attribute pairs).

\begin{tabular}{llll}
\hline Stakeholder Pairs & Minimum & Maximum & Root Mean Square \\
\hline StuFac & 0.1 & 31.4 & 13.41 \\
StuInd & 0.2 & 25.4 & 9.1 \\
FacInd & 0.0 & 19.7 & 9.0 \\
\hline
\end{tabular}

Note. StuFac-student and faculty; StuInd-student and industry; FacInd-faculty and industry.

Overall, the findings suggest that there is not much variation in the patterns of engineering stakeholder mean dependency ratings of pairs of graduate attribute both relatively and absolutely among stakeholder groups. As a result, the similarities of the graduate attributes and the clusters of the graduate attributes were analyzed using the data derived from all stakeholders (a holistic analysis), rather than from individual stakeholder groups (case analysis).

\subsection{CEAB Graduate Attribute Clusters}

Multidimensional Scaling (MDS) was used to evaluate how the perceived similarities of the CEAB graduate attributes cluster together across all engineering stakeholders. A two-dimensional plot was determined to be most appropriate for analysis. Four clusters of attributes can be perceived in four quadrants in the common space (see Figure 4.1). 


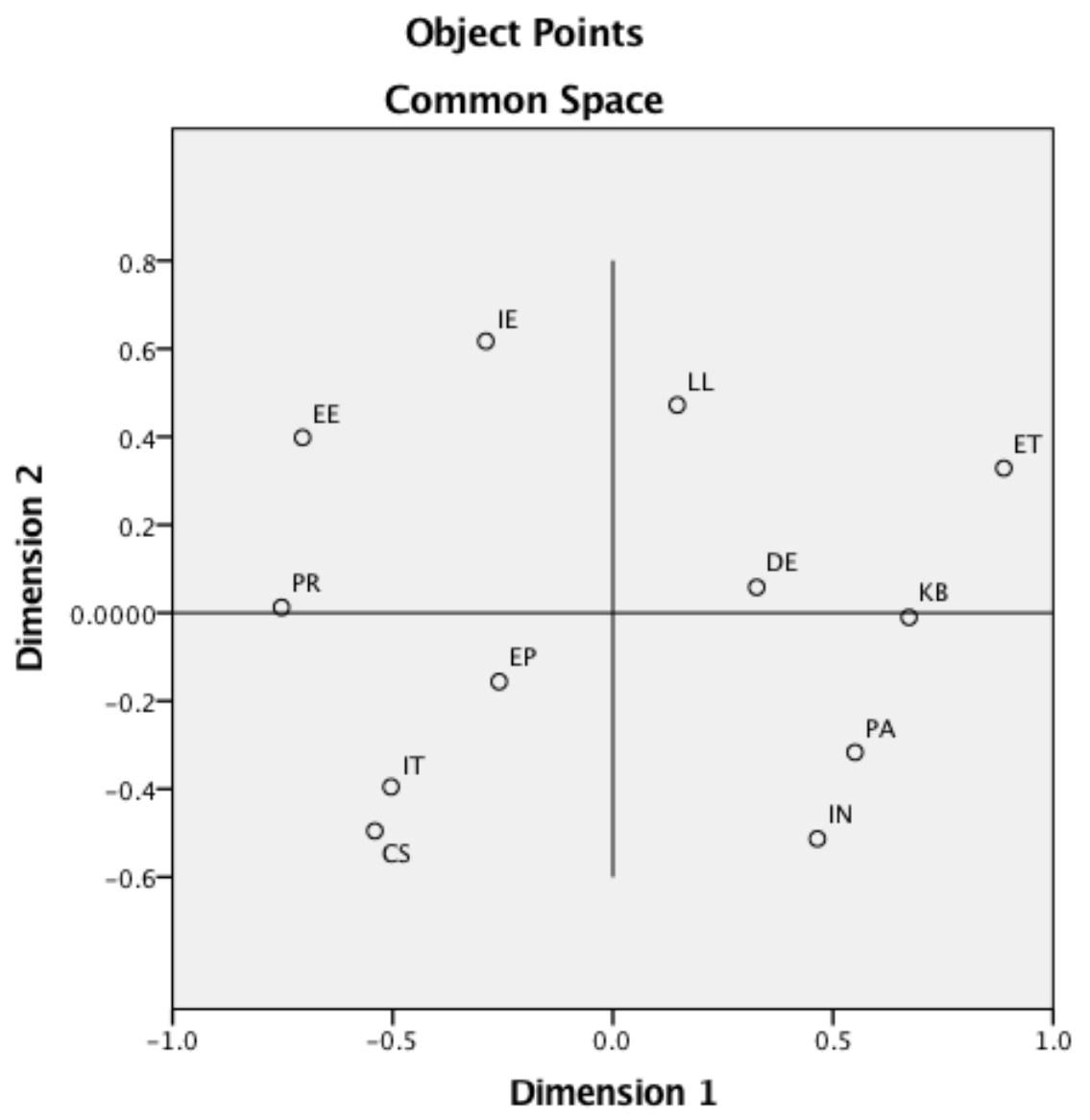

Figure 4.1. Common space of engineering stakeholders $C E A B$ graduate attributes similarity data in a 2-dimensional MDS analysis.

Note. 1. KB=Knowledge Base for Engineering; PA=Problem Analysis; IN=Investigation; $\mathrm{DE}=$ Design; ET=Use of Engineering Tools; IT=Individual and Teamwork; CS=Communication Skills;

$\mathrm{PR}=$ Professionalism; IE=Impact of Engineering; $\mathrm{EE}=\mathrm{Ethics}$ and Equity; $\mathrm{EP}=\mathrm{Economics}$ and Project Management; LL=Lifelong Learning.

In the common space, Investigation, Problem Analysis, and Knowledge Base for Engineering are found in the lower right quadrant (quadrant 4), with medium to high values in Dimension 1, and low to medium values in Dimension 2. Communication Skills, Individual and Teamwork, and Economics and Project Management are found in the lower left quadrant (quadrant 3), with a low to medium dimensionality in both Dimensions 1 and 2. Professionalism, Ethics and Equity, and Impact of Engineering on Society and the Environment are found in the upper left quadrant (quadrant 2), with low to medium values in Dimension 1 and medium to high values in Dimension 2. Design, Lifelong Learning and Use of Engineering Tools are found in the upper right quadrant (quadrant 1), with medium to high dimensionality in both Dimensions 1 and 2. Overall, Individual and Teamwork and Communication Skills, and Problem Analysis and Investigation form the two closest clusters.

It is important to note that the axes have no intrinsic value: 'the coordinate axes in MDX are simply a device to 'hang' the points within the m-dimensional space ${ }^{58}$ (p. 23). The axes assist in interpreting the 
dimensions and 'directions' within the space, and in identifying potential clusters ${ }^{58}$ (p. 23). MDS is intended for use as an exploratory interpretation of the data, where 'visual inspection is often enough in itself $^{58}$ (p. 23). However, it is recommended to confirm interpretations. In this study, the potential cluster interpretations offered are substantiated by the literature and a reasonable consideration of engineering curricula.

\subsection{Discussion}

\subsection{CEAB Graduate Attribute Dependencies as Perceived by Engineering Stakeholders}

Engineering stakeholders chose Individual and Teamwork as having the highest dependency on Communication Skills in the graduate attribute mean dependency ratings $(88.7 \%$ (18.5 SD). These data, in conjunction with their top relative importance ratings in this study (findings that will be reported on in a future publication) and in the research literature, stress the importance of these attributes and the relevance of this pairing within the engineering curriculum. The highest rated dependencies overall (between 79\%-87\%) for all engineering stakeholders were found between Design on Knowledge Base for Engineering and on Problem Analysis; Problem Analysis on Knowledge Base for Engineering; Professionalism on Communication Skills and on Ethics and Equity; Individual and Teamwork on Professionalism; Communication Skills on Individual and Teamwork; Impact of Engineering on Society and the Environment on Ethics and Equity; and Ethics and Equity on Professionalism.

The lowest dependency rating for all engineering stakeholders in this case was Engineering Tools on Ethics and Equity (35.3\% (32.4 SD)).

\subsection{CEAB Graduate Attributes Clusters}

Some of the clusters identified in the MDS results reflect parts of the engineering curricula in the Faculty of Engineering at the University of Manitoba. For example, it is the engineering communication course where elements of the graduate attribute, Communication Skills are taught and assessed with Individual and Teamwork and Economics and Project Management. As well, Investigation and Problem Analysis are found linked in the pedagogy, as is Ethics and Equity with Professionalism and with Impact of Engineering on Society and the Environment, particularly when it comes to topics such as sustainability and diversity. The findings in this research support these curricular designs, and the explicit improvement and/or design of engineering curricula informed by these clusters.

A surprising finding was the cluster of Lifelong Learning with Design and Use of Engineering Tools. This cluster is noteworthy due to the reputation of Lifelong Learning in the research as a difficult competency to teach and assess, better suited to appraisal a priori ${ }^{3}$. It is the competency that could be considered as having the most unnatural fit with engineering and engineering identity. It has been the competency that has given engineering educators the most cause for consternation, particularly when it comes to teaching and assessing it in engineering curricula ${ }^{7,59}$. In fact, it caused so much angst that several years ago it was temporarily removed from the ABET list of student learning outcomes ${ }^{60}$. However, enough outcry was heard ${ }^{61-62}$ that lifelong learning was reintroduced to the ABET 
engineering learning outcomes. This demonstrates that lifelong learning is evidently considered valuable for engineers and engineering education, and essentially worth the assessment struggle.

Design, on the other hand, is often considered the mecca of the engineering profession. It is noteworthy that in the findings of this research study, Lifelong Learning occupies the same MDS perceptual space as Design and Use of Engineering Tools. This finding offers another way to think about and implement Lifelong Learning in addition to the information literacy role that it is often relegated to play in the engineering curriculum. These research findings emphasize process, inherent in the knowledge, skills, attitudes, values, and behaviours of Design and Use of Engineering Tools, which are built on the foundation of problem solving. This reminds educators that design is a process, embarked upon to solve a problem, the skills of which have been said to evolve over a lifetime. Clustering Lifelong Learning with Design and Use of Engineering Tools in engineering education stresses the importance of keeping abreast of the skills and tools of engineering needed in this complex, fast-paced, mutable world, in order to successfully solve the global problems that we face today.

\subsection{Conceptual and Theoretical Framework for the CEAB Graduate Attributes}

One of the objectives of this study was to develop a conceptual/theoretical framework for the CEAB graduate attributes that would inform engineering curricular design and improvement. Rather than listing 12 individual graduate attributes, using these data, engineering educators can conceptualize clusters of knowledge, skills, attitudes, values, and behaviours that can assist thinking about engineering pedagogy and curricular design.

Considering the four quadrants defined by the dimensionality that may be interpreted from the MDS common space, the CEAB graduate attributes can be interpreted as representing four clusters. The bottom right cluster (quadrant 4) could be termed Problem Solving Skills, as problem solving is considered a quintessential engineering skill ${ }^{63}$ and is a top engineering competency ${ }^{53}$. This cluster would be comprised of the graduate attributes, Knowledge Base for Engineering, Investigation, and Problem Analysis. The bottom left cluster (quadrant 3), with Communication Skills, Individual and Teamwork, and Economics and Project Management, and the addition of the behavioural elements of Professionalism (i.e., the indicators, exhibits behaviour expected of a Professional Engineer) could be redefined as the Interpersonal Skills, which are demarcated as communication and interaction with people and flagged as one factor for successful employability ${ }^{64}$. The top left cluster (quadrant 2) could be called Ethical Reasoning, a term taken from Sheppard, Pellegrino, and Olds $(2008)^{65}$, deemed essential for $21^{\text {st }}$ century engineering, and containing the more cognitive aspects of Professionalism (i.e., the indicators, understands the role of the engineering profession in society and the responsibility of the Professional Engineer in protection of the public; and knows relevant codes, laws and regulations), along with Ethics and Equity, and Impact of Engineering on Society and the Environment. The upper right cluster (quadrant 1) could be termed Creativity and Innovation, the latter which Radcliffe (2005) ${ }^{66}$ describes as the 'meta-attribute' for engineers, with both capabilities stressed in the literature as critical engineering competencies ${ }^{45,67}$. It would encompass the engineering skills Design, Use of Engineering Tools, and Lifelong Learning (see Figure 5.1). 


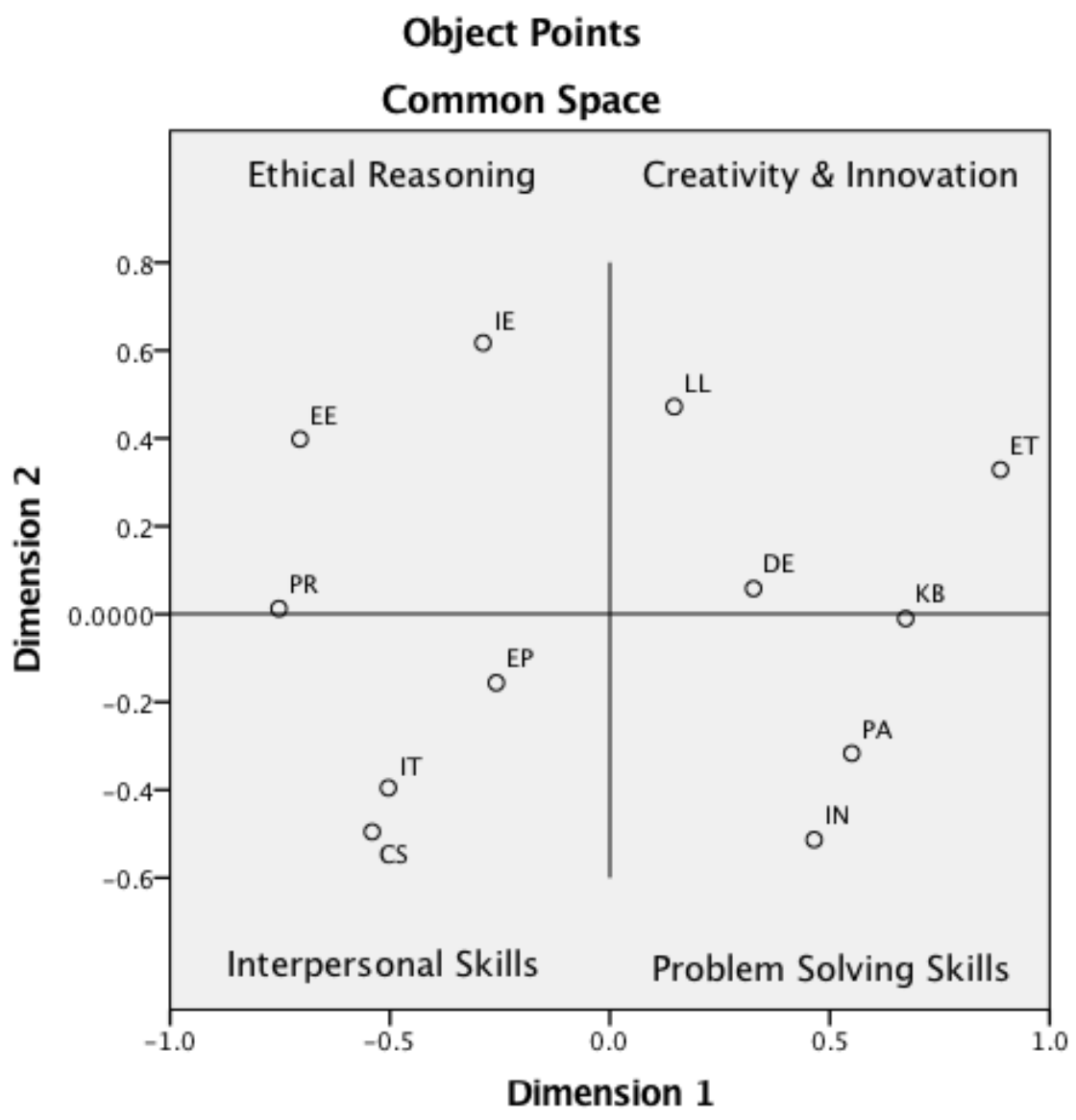

Figure 5.1. Conceptualization of four clusters of engineering competencies in the MDS common space.

Within these clusters, engineering educators can develop the engineering competencies necessary for $21^{\text {st }}$ century practice. As research underscores, engineering educators need to provide authentic educational experiences that facilitate students in acquiring all the competencies necessary to be successful engineers who are ready, willing, and able to be the ambassadors between society and technology in tackling today's wicked problems. Conceptualizing engineering competencies as interconnected rather than as individual attributes supports 'coordinating competencies' to emulate engineering practice (p. 504) $)^{51}$. This could motivate engineering educators to design learning environments using experiential learning that draw on clusters of competencies, rather than implementing curricula that inauthentically isolate engineering knowledge, skills, attitudes, values, and behaviours. Considering CEAB graduate attributes not simply as a list, but rather, as a framework, stresses the importance of all the domains required for good engineering:

All engineering is, of necessity, both technical and social... Good engineering (as in engineering which is effective) demands the thorough integration of these elements in ways that transcend conventional dichotomies [50, p. 351 emphasis in original]. The knowledge mobilized in the course of engineering . . . is never "just technical" with "the social" bolted on. Rather, these two dimensions are in a very practical sense inseparable... Since the two are inseparable in everyday engineering practice, the boundaries drawn between them are inevitably arbitrary. (p. 491) 
Society's challenges compel new engineering graduates to 'be all things' - knowledgeable, skillful, and emotionally intelligent, showing prowess in cognitive, psychomotor, and affective abilities - which requires curricula that facilitates engineering students to interact with a myriad of knowledge, skills, attitudes, values, and behaviours simultaneously. This recalls the work of Bloom, Engelhart, Furst, Hill and Krathwohl (1956), and their three Domains of Learning: Cognitive, Psychomotor, and Affective, which can be used to theorize the CEAB graduate attributes in the MDS common space, and their directionality through lower to higher order learning domains ${ }^{68}$. This aspect of the research will be presented in depth in a future publication.

\subsection{Conclusion and Recommendations}

This research paper presented the findings from a portion of an exploratory case study that investigated the dependencies of engineering competencies in practice from the perspectives of engineering student, faculty, and industry members associated with the Faculty of Engineering at the University of Manitoba. The research questions and quantitative questionnaire method were designed to examine how the CEAB (Canadian Engineering Accreditation Board) graduate attributes depend on one another for an EIT (Engineer-in-Training) at the being of her/his career. A closed ended questionnaire was used to collect data on the percentage of one graduate attribute on another graduate attribute. The data were analyzed using descriptive and inferential statistics to evaluate how much the pattern of perceived dependencies of the CEAB graduate attributes varied between engineering stakeholder groups, and to determine how they cluster based on their pattern of perceived dependencies.

The graduate attribute dependency findings demonstrated some understandings that are reflected by the literature, as well as new understandings for how the CEAB graduate attributes cluster together, and how the clusters may be interpreted. One of the chief recommendations that arises from this research is to re-conceptualize the $\mathrm{CEAB}$ graduate attributes from a list into a framework that supports the interconnectivity of engineering competencies to emulate engineering practice. Suggested by these findings is a clustering of the CEAB graduate attributes into four quadrants: Interpersonal Skills, Problem Solving Skills, Ethical Reasoning, and Creativity and Innovation. This framework could be used as a tool for curricular improvement and development, authentically representing the inherent interconnectivity of engineering competencies in practice.

\section{References}

1. Seniuk Cicek, J., Ingram, S., Mann, D., and Renaud, R. D. 2017. "Investigating the Relative Importance of the CEAB Graduate Attributes: Study Design and Initial Findings.” In Proceedings of the Canadian Engineering Education Association Conference: Innovation and Diversity in Engineering Education (CEEA/ACEG), 9 pp., 4-7 June. Toronto, ON: OJS/PKP. https://ceea.ca/en/publications/

2. International Engineering Alliance. 2013. "Graduate Attributes and Professional Competencies: Version 3: 21 June 2013.” International Engineering Alliance. http://www.ieagreements.org/assets/Uploads/Documents/Policy/Graduate-Attributes-and-ProfessionalCompetencies.pdf 
3. Shuman, L. J., M. Besterfield-Sacre, and J. McGourty. 2005. "The ABET "Professional Skills" - Can They Be Taught? Can They Be Assessed?” Journal of Engineering Education 94 (1): 41-55. doi: 10.1002/j.21689830.2005.tb00828.x.

4. Siri Johnson, C. 2006. "The Analytic Assessment of Online Portfolios in Undergraduate Technical Communication: A Model.” Journal of Engineering Education 95 (4): 279-287. doi: 10.1002/j.21689830.2006.tb00903.x.

5. Roselli, R.J., and S. P. Brophy. 2006. "Effectiveness of Challenge-Based Instruction in Biomechanics." Journal of Engineering Education 95 (4): 311-324. doi: 10.1002/j.2168-9830.2006.tb00907.x.

6. Loui, M. C. 2006. "Assessment of an Engineering Ethics Video: Incident at Morales.” Journal of Engineering Education 95 (1): 85-91. doi: 10.1002/j.2168-9830.2006.tb00879.x.

7. Jiusto, S., and Di Biasio, D. 2006. "Experiential Learning Environments: Do They Prepare Our Students to be SelfDirected, Lifelong Learners?” Journal of Engineering Education 95 (3): 195-204. doi: 10.1002/j.21689830.2006.tb00892.x.

8. Yalvac, B., H. D. Smith, J. B. Troy, and P. L. Hirsch. 2007. "Promoting Advanced Writing Skills in an UpperLevel Engineering Class.” Journal of Engineering Education 96 (2): 117-128. doi: 10.1002/j.21689830.2007.tb00922.x.

9. Colby, A., and W. M. Sullivan. 2008. "Ethics Teaching in Undergraduate Engineering Education." Journal of Engineering Education 97 (3): 327-338. doi: 10.1002/j.2168-9830.2008.tb00982.x.

10. Hanson J. H., and J. M. Williams. 2008. "Using Writing Assignments To Improve Self-Assessment And Communication Skills In An Engineering Statics Course.” Journal of Engineering Education 97 (4): 515-529. doi: 10.1002/j.2168-9830.2008.tb00997.x.

11. Barry, B. E., and M. W. Ohland. 2009. "Applied Ethics in the Engineering, Health, Business, and Law Professions: A Comparison.” Journal of Engineering Education 98 (4): 377-388. doi: 10.1002/j.2168-9830.2009.tb01034.x.

12. Jonassen, D. H., D. Shen, R. M. Marra, Y. H. Cho, J. L. Lo, and V. K. Lohani. 2009. "Engaging and Supporting Problem Solving in Engineering Ethics." Journal of Engineering Education 98 (3): 235-254. doi: 10.1002/j.21689830.2009.tb01022.x.

13. Zafft, C. R., S. G. Adams, and G. S. Matkin. 2009. "Measuring Leadership in Self-Managed Teams Using the Competing Values Framework.” Journal of Engineering Education 98 (3): 273-282. doi: 10.1002/j.21689830.2009.tb01024.x.

14. Hsiung, C. M. 2010. 'Identification of Dysfunctional Cooperative Learning Teams Based on Students' Academic Achievement." Journal of Engineering Education 99 (1): 45-54. doi: 10.1002/j.2168-9830.2010.tb01041.x.

15. Lathem, S., M. Neumann, and N. Hayden. 2011. "The Socially Responsible Engineer: Assessing Student Attitudes of Roles and Responsibilities.” Journal of Engineering Education 100 (3): 444-471. doi: 10.1002/j.21689830.2011.tb00022.x.

16. Beach, D., and S. M. McCahan. 2014. "Review of Learning Outcomes Developed for Graduate Attributes." In Proceedings of the Canadian Engineering Education Association Conference (CEEA), 1 pp., 8-11 June. Canmore, AB: OJS/PKP. https://ojs.library.queensu.ca/index.php/PCEEA/issue/view/543

17. Behdinan, K., R. Pop-Iliev, and J. Foster. 2014. "What Constitutes a Multi-Disciplinary Capstone Design Course? Best Practices, Successes and Challenges." In Proceedings of the Canadian Engineering Education Association Conference (CEEA), 5 pp., 8-11 June. Canmore, AB: OJS/PKP. https://ojs.library.queensu.ca/index.php/PCEEA/issue/view/543 
18. Brennan, R.W., M. Eggermont, W. Rosehart, A. K. Deacon, N. Larson, and T. A. O'Neill. 2014. "Assessing LifeLong Learning in a First-Year Design and Communication Course." In Proceedings of the Canadian Engineering Education Association Conference (CEEA), 4 pp., 8-11 June. Canmore, AB: OJS/PKP. https://ojs.library.queensu.ca/index.php/PCEEA/issue/view/543

19. Buchal, R. O., N. Billingsley, A. Bullock and P. Poulin. 2014. "The Lac-MéGantic Train Disaster as a Basis for a Design Project that Emphasizes Safety." In Proceedings of the Canadian Engineering Education Association Conference (CEEA), 6 pp., 8-11 June. Canmore, AB: OJS/PKP. https://ojs.library.queensu.ca/index.php/PCEEA/issue/view/543

20. Caines, S., L. Lye, and M. R. Hossain. 2014. "Teaching Assistant Training to Enhance Graduate Engineering Education." In Proceedings of the Canadian Engineering Education Association Conference (CEEA), 4 pp., 8-11 June. Canmore, AB: OJS/PKP. https://ojs.library.queensu.ca/index.php/PCEEA/issue/view/543

21. Caines, S., and J. Shirokoff. 2014. "The Development and Teaching of Corrosion Course in an Engineering Program." In Proceedings of the Canadian Engineering Education Association Conference (CEEA), 4 pp., 8-11 June. Canmore, AB: OJS/PKP. https://ojs.library.queensu.ca/index.php/PCEEA/issue/view/543

22. Calderon, F., L. Yu, and T. Willink. 2014. "Using Arts in Engineering to Develop Graduate Attributes in an Outcome-Based Approach." In Proceedings of the Canadian Engineering Education Association Conference (CEEA), 7 pp., 8-11 June. Canmore, AB: OJS/PKP. https://ojs.library.queensu.ca/index.php/PCEEA/issue/view/543

23. Dew, S., R. Driver, G. Thomas, M. Mandal, and P. Choi. 2014. "Scalability of a Graduate Attributes and Continuous Improvement Process." In Proceedings of the Canadian Engineering Education Association Conference (CEEA), 6 pp., 8-11 June. Canmore, AB: OJS/PKP. https://ojs.library.queensu.ca/index.php/PCEEA/issue/view/543

24. Ferens, K., J. Seniuk Cicek, N. Sepehri, W. Kinsner, J.P. Burak, A. Parker, D. McNeill, et al. 2014. "Industry Forum III: Towards a Common Language." In Proceedings of the Canadian Engineering Education Association Conference (CEEA), 7 pp., 8-11 June. Canmore, AB: OJS/PKP. https://ojs.library.queensu.ca/index.php/PCEEA/issue/view/543

25. Godri-Politt, K. and G. W. Norval. 2014. "A Module for Teaching Risk Management." In Proceedings of the Canadian Engineering Education Association Conference (CEEA), 1 pp., 8-11 June. Canmore, AB: OJS/PKP. https://ojs.library.queensu.ca/index.php/PCEEA/issue/view/543

26. Hsiao, A. 2014. "Sustainability Entrepreneurship in Engineering." In Proceedings of the Canadian Engineering Education Association Conference (CEEA), 5 pp., 8-11 June. Canmore, AB: OJS/PKP. https://ojs.library.queensu.ca/index.php/PCEEA/issue/view/543

27. Kaupp, J., and B. Frank. 2014a. "Approaching the Loop: A Brief Review of Effective Practices in Continuous Program Improvement." In Proceedings of the Canadian Engineering Education Association Conference (CEEA), 6 pp., 8-11 June. Canmore, AB: OJS/PKP. https://ojs.library.queensu.ca/index.php/PCEEA/issue/view/543

28. Kaupp, J., and B. Frank. 2014b. "Evaluation of Software Tools Supporting Outcomes-Based Continuous Program Improvement Processes: Part 2." In Proceedings of the Canadian Engineering Education Association Conference (CEEA), 10 pp., 8-11 June. Canmore, AB: OJS/PKP. https://ojs.library.queensu.ca/index.php/PCEEA/issue/view/543

29. Kaupp, J., N. Simper, and B. Frank. 2014. "Triangulated Authentic Assessment in the HEQCO Learning Outcomes Assessment Consortium." In Proceedings of the Canadian Engineering Education Association Conference (CEEA), 10 pp., 8-11 June. Canmore, AB: OJS/PKP.

https://ojs.library.queensu.ca/index.php/PCEEA/issue/view/543 
30. Kennedy, D., K. Abercrombie, M. Bollo, and J. Jenness. 2014. "Reconciling Graduate Attribute Assessment with Existing Outcome-Based Assessment." In Proceedings of the Canadian Engineering Education Association Conference (CEEA), 6 pp., 8-11 June. Canmore, AB: OJS/PKP.

https://ojs.library.queensu.ca/index.php/PCEEA/issue/view/543

31. Kishawy, H. A., T. Sidhu, R. Pop-Iliev, M. A. Rosen, D. Zhang and Q. H. Mahmoud. 2014. "Meeting the Outcome-Based CEAB Accreditation Criteria: Engineering Programs at UOIT." In Proceedings of the Canadian Engineering Education Association Conference (CEEA), 7 pp., June 8-11. Canmore, AB: OJS/PKP. https://ojs.library.queensu.ca/index.php/PCEEA/issue/view/543

32. Lye, L. 2014. "Development and Use of Simulation Apps and Physical Toys for Teaching Experimental Design Principles." In Proceedings of the Canadian Engineering Education Association Conference (CEEA), 6 pp., 8-11 June. Canmore, AB: OJS/PKP. https://ojs.library.queensu.ca/index.php/PCEEA/issue/view/543

33. Mackie, M. L., and D. D. Mann. 2014. "Alumni Survey for University of Manitoba Department of Biosystems Engineering." In Proceedings of the Canadian Engineering Education Association Conference (CEEA), 5 pp., 811 June. Canmore, AB: OJS/PKP. https://ojs.library.queensu.ca/index.php/PCEEA/issue/view/543

34. Marasco, E., L. Behjat, and M. Eggermont. 2014. "Engaging First Year Students Through Cross Disciplinary Design Projects." In Proceedings of the Canadian Engineering Education Association Conference (CEEA), 4 pp., 8-11 June. Canmore, AB: OJS/PKP. https://ojs.library.queensu.ca/index.php/PCEEA/issue/view/543

35. Moazzen, I., M. Miller, P. Wild, L. Jackson and A. Hadwin. 2014. "Engineering Design Survey." In Proceedings of the Canadian Engineering Education Association Conference (CEEA), 7 pp., 8-11 June. Canmore, AB: OJS/PKP. https://ojs.library.queensu.ca/index.php/PCEEA/issue/view/543

36. Nelson, N. 2014. "Achieving Graduate Attributes Through Project-Based Learning." In Proceedings of the Canadian Engineering Education Association Conference (CEEA), 7 pp., 8-11 June. Canmore, AB: OJS/PKP. https://ojs.library.queensu.ca/index.php/PCEEA/issue/view/543

37. Orr, V., S. Barghi, and R. Buchal. 2014. "Process Safety Management Learning Module." In Proceedings of the Canadian Engineering Education Association Conference (CEEA), 7 pp., 8-11 June. Canmore, AB: OJS/PKP. https://ojs.library.queensu.ca/index.php/PCEEA/issue/view/543

38. Peto, L., and C. Geddert. 2014. "Using Career Education to Help Students Build and Articulate Employability Skills." In Proceedings of the Canadian Engineering Education Association Conference (CEEA), 7 pp., 8-11 June. Canmore, AB: OJS/PKP. https://ojs.library.queensu.ca/index.php/PCEEA/issue/view/543

39. Spracklin-Reid, D., and A. Fisher. 2014. "Curriculum Mapping in Engineering Education: Linking Attributes, Outcomes and Assessments." In Proceedings of the Canadian Engineering Education Association Conference (CEEA), 1 pp., 8-11 June. Canmore, AB: OJS/PKP. https://ojs.library.queensu.ca/index.php/PCEEA/issue/view/543

40. Spracklin-Reid, D., C. Koenig, S. Hurley, and P. Phillips. 2014. "Teaching with Technology in Engineering Education." In Proceedings of the Canadian Engineering Education Association Conference (CEEA), 4 pp., 8-11 June. Canmore, AB: OJS/PKP. https://ojs.library.queensu.ca/index.php/PCEEA/issue/view/543

41. Spracklin-Reid, D., A. Ryan, and A. Smith. 2014. "Building Relationships Between Engineering and the Trades Through Service Learning." In Proceedings of the Canadian Engineering Education Association Conference (CEEA), 5 pp., 8-11 June. Canmore, AB: OJS/PKP. https://ojs.library.queensu.ca/index.php/PCEEA/issue/view/543

42. Stagner, J., and J. Johrendt. 2014. "Mechanical Engineering Capstone Design Course - CEAB Accreditation Outcomes Assessment." In Proceedings of the Canadian Engineering Education Association Conference (CEEA), 7 pp., 8-11 June. Canmore, AB: OJS/PKP. https://ojs.library.queensu.ca/index.php/PCEEA/issue/view/543 
43. Oliver, B. 2013. "Graduate Attributes as a Focus for Institution-Wide Curriculum Renewal: Innovations and Challenges." Higher Education Research and Development, 32 (3), 450-463.

http://dx.doi.org/10.1080/07294360.2012.682052

44. Leggett, M., A. Kinnear, M. Boyce, and I. Bennett. 2004. "Student and Staff Perceptions of the Importance of Generic Skills in Science." Higher Education Research and Development 23 (3), 295-312. doi: $10.1080 / 0729436042000235418$.

45. Male, S. 2010. "Generic Engineering Competencies: A Review and Modelling Approach." Education Research and Perspectives 37 (1): 25 - 51. http://erpjournal.net/wp-content/uploads/2012/07/ERPV37-1 Male-S.-2010.Generic-Engineering-Competencies.pdf

46. Male, S. A., Bush, M. B. and Chapman, E. S. 2011a. "An Australian Study of Generic Competencies Required by Engineers.” European Journal of Engineering Education 36 (2): 151-163. http://dx.doi.org/10.1080/03043797.2011.569703

47. Male, S. A., M. B. Bush, and E. S. Chapman. 2011b. "Understanding Generic Engineering Competencies." Australasian Journal of Engineering Education 17 (3), 147-156. http://dx.doi.org/10.1080/22054952.2011.11464064

48. Pons, D. 2016. "Relative Importance of Professional Practice and Engineering Management Competencies." European Journal of Engineering Education 41 (5): 530-547. doi: 10.1080/03043797.2015.1095164.

49. Ebrahiminejad, H. 2017. "A Systematized Literature Review: Defining and Developing Engineering Competencies." In Proceedings American Society for Engineering Education ASEE's $123^{\text {rd }}$ Annual Conference and Exposition: Jazzed About Engineering Education, 12 pp., 26-29 June. New Orleans, LA.

50. Meenakshi, S., and S. Mohanty. 2017. "Importance Versus Achieved: A Cross-Sectional Study on Engineering Students' Perception on Generic Attributes." Journal of Engineering Education Transformations 31 (1): 48-55. ISSN 2349-2473, eISSN 2394-1707.

51. Passow, H. J., and C. H. Passow. 2017. "What Competencies Should Undergraduate Engineering Programs Emphasize? A Systematic Review." Journal of Engineering Education 106 (3): 475-526. doi: 10.1002/jee.20171.

52. Nguyen, D. Q. 1998. "The Essential Skills and Attributes of an Engineer: A Comparative Study of Academics, Industry Personnel and Engineering Students." Global Journal of Engineering Education 2 (1): 65-75. http://citeseerx.ist.psu.edu/viewdoc/download?doi=10.1.1.124.1502\&rep=rep1\&type=pdf

53. Passow, H. 2012. "Which ABET Competencies do Engineering Graduates Find Most Important in Their Work?" Journal of Engineering Education 101 (1): 95-118. doi: 10.1002/j.2168-9830.2012.tb00043.x.

54. Van Note Chism, N., E. Douglas, and W. J. Hilson, Jr. 2008. Qualitative Research Basics: A Guide for Engineering Educators. Rigorous Research in Engineering Education. USA: National Science Foundation. DUE0341127. https://crlte.engin.umich.edu/wp-content/uploads/sites/7/2013/06/Chism-Douglas-Hilson-QualitativeResearch-Basics-A-Guide-for-Engineering-Educators.pdf

55. Creswell, J. W. 2013. Qualitative Inquiry and Research Design: Choosing Among Five Approaches, 3rd ed. L.A.: Sage.

56. NCSS. 2017. "Multidimensional Scaling." Chap. 435 in NCSS Statistical Software. NCSS, LLC. https://ncsswpengine.netdna-ssl.com/wpcontent/themes/ncss/pdf/Procedures/NCSS/Multidimensional_Scaling.pdf

57. Borg, I., P. J. F. Groenen, and P. Mair. 2013. Applied Multidimensional Scaling. Heidelberg: Springer.

58. Jacoby, W. G., and D. J. Ciuk. 2014. Multidimensional Scaling: An Introduction. http://polisci.msu.edu/jacoby/research/scaling/intromds/Jacoby-Ciuk,\%20MDS,\%20V2,\%2010-29-14.pdf 
59. Seniuk Cicek, J., S. Ingram, and M. Friesen. 2016. "On Becoming an Engineer: The Essential Role of Lifelong Learning Competencies." In Proceedings of the American Society for Engineering Education $123^{\text {rd }}$ Annual Conference and Exposition: Jazzed about Engineering Education, 17 pp., 26-29 June. New Orleans, LA.

60. Waters, C. 2007. "Work in Progress - Blackboard Tracking, Can This Be a Method of ABET Outcome i Assessment." In 37th Annual ASEE/IEEE Frontiers in Education Conference: Global Engineering: Knowledge Without Borders, Opportunities without Passports. 10-13 October. Milwaukee, WI. doi: 10.1109/FIE.2007.4417876.

61. Flaherty, C. 2015. "Watered-Down Gen Ed for Engineers?" Inside Higher Ed. https://www.insidehighered.com/news/2015/06/26/faculty-members-criticize-proposed-changes-gen-edaccreditation-standards-engineers

62. Rogers, J. 2015. "Jamie Rogers, ABET president, explains the reasoning behind proposed changes to Criteria 3 and 5." ABET. http://www.abet.org

63. Hanrahan, H. 2008. "The Washington Accord: History, Development, Status and Trajectory." In 7th ASEE Global Colloquium On Engineering Education, 9 pp. Cape Town, South Africa, 19-23 October.

64. SkillsYouNeed. 2017. “Interpersonal Skills.” SkillsYouNeed. https://www.skillsyouneed.com/interpersonalskills.html

65. Sheppard, S. D., J. W. Pellegrino, and B. M. Olds. 2008. “On Becoming a $21^{\text {st }}$ Century Engineer.” Journal of Engineering Education 97 (3): 231 - 234. doi: 10.1002/j.2168-9830.2008.tb00972.x.

66. Radcliffe, D. F. 2005. "Innovation as a Meta Attribute for Graduate Engineers." International Journal of Engineering Education 21: 194-199. http://citeseerx.ist.psu.edu/viewdoc/download?doi=10.1.1.157.9426\&rep=rep1\&type=pdf

67. Robinson, M. A., P. R. Sparrow, C. Clegg, and K. Birdi. 2005. "Design Engineering Competencies: Future Requirements and Predicted Changes in the Forthcoming Decade." Design Studies 26 (2005): 123-153. doi:10.1016/j.destud.2004.09.004.

68. Bloom, B. S., M. D. Engelhart, E. J. Furst, W. H. Hill, and D. R. Krathwohl. 1956. Taxonomy of Educational Objectives: The Classification of Educational Goals. Handbook 1: The Cognitive Domain, 1st Edition. New York: Longmans, Green and Co. 